\title{
Morfologia dos ossos do membro torácico do tamanduá-bandeira
}

\author{
Imara Guimarães Lima ${ }^{1}$ \\ Daniel Arrais Biihrer ${ }^{1}$ \\ Gregório Corrêa Guimarães ${ }^{1 *}$ \\ Karen Caetany Moreira ${ }^{1}$ \\ Matheus Camargos de Britto Rosa ${ }^{1}$ \\ Arlei José Birck ${ }^{2}$ \\ Fabrício Singaretti de Oliveira ${ }^{3}$ \\ Camila Souza de Oliveira Guimarães ${ }^{4}$ \\ ${ }^{1}$ Departamento de Medicina Veterinária, Universidade Federal de Lavras \\ Caixa Postal 3037, CEP 37200-000, Lavras - MG, Brasil \\ ${ }^{2}$ Departamento de Medicina Veterinária, Universidade Federal do Paraná, Palotina - PR, Brasil \\ ${ }^{3}$ Departamento de Morfologia e Fisiologia Animal \\ Universidade Estadual Paulista Júlio de Mesquita Filho, Jaboticabal - SP, Brasil \\ ${ }^{4}$ Universidade Federal do Triângulo Mineiro, Uberaba - MG, Brasil \\ * Autor para correspondência \\ gregorio@dmv.ufla.br
}

Submetido em 10/06/2013

Aceito para publicação em 30/07/2013

\section{Resumo}

O tamanduá-bandeira possui uma pelagem cinza acastanhada com tons brancos e negros, seu crânio é alongado, cilíndrico e com ausência de dentes. Sua cauda é longa, com pelos grossos e compridos, assemelhandose a uma bandeira. Trata-se de uma espécie ameaçada, devido à constante degradação do seu hábitat, além de mortes causadas por queimadas e atropelamentos. Assim, o objetivo deste artigo foi descrever a morfologia dos ossos do membro torácico do Myrmecophaga tridactyla, enfocando seus principais acidentes ósseos. Foram utilizados dois espécimes de tamanduá-bandeira coletados em rodovias no estado de Minas Gerais, mortos após atropelamento. A escápula, o úmero, o rádio, a ulna e os ossos da mão apresentaram características próprias adaptadas ao estilo de vida e aos hábitos da espécie. No geral, a escápula se assemelha à dos seres humanos e o úmero é semelhante ao do tatu, o rádio e a ulna exibem superfícies articulares que possibilitam amplos movimentos de rotação no antebraço, os ossos do carpo também se assemelham em número e forma aos dos seres humanos e os dedos são bem desenvolvidos no tamanduá-bandeira, dotados de garras longas, fortes e cortantes, principalmente a do terceiro dedo. Assim, a descrição anatômica dos ossos do membro torácico do tamanduá-bandeira mostrou-se importante, aprofundando tanto o entendimento dos aspectos funcionais do membro torácico como da anatomia comparada de animais silvestres.

Palavras-chave: Acidentes ósseos; Anatomia; Membro torácico; Myrmecophaga tridactyla 


\section{Abstract}

Morphology of the thoracic limb bones in the giant anteater. The giant anteater has a grayish-brown pelage with white and black tones, its skull is elongated, cylindrical, and there are no teeth. Its tail is long, with thick and long bristles, resembling a flag. This is an endangered species, due to the constant degradation of its habitat, in addition to deaths caused by fires and roadkills. Thus, this paper aimed to describe the morphology of the thoracic limb bones in Myrmecophaga tridactyla, focusing on its main bone accidents. We used two specimens of giant anteater collected on highways in the state of Minas Gerais, Brazil, after death due to being run over. The scapula, humerus, radius, ulna, and the hand bones showed particular characteristics adapted to the species' lifestyle and habits. In general, the scapula resembles that in human beings and the humerus is similar to that in armadillo, the radius and ulna exhibit articular surfaces which enable a wide range of rotational movements in the forearm, the carpal bones are also similar in number and shape to those in human beings, and the fingers are well developed in the giant anteater, having long, strong and sharp claws, especially in the third finger. Thus, the anatomical description of the thoracic limb bones in the giant anteater showed to be important, providing a deeper understanding both of the functional aspects of the thoracic limb and the comparative anatomy of wild animals.

Key words: Anatomy; Bone accidents; Thoracic member; Myrmecophaga tridactyla

\section{Introdução}

Pertencente à Ordem Pilosa e à Família Myrmecophagidae, o Myrmecophaga tridactyla é conhecido popularmente como tamanduá-bandeira, papa-formigas, tamanduá-açu (EMMONS; FEER, 1997) e tamanduá-cavalo (CHEBEZ, 1994). É o maior representante desta família, podendo atingir 2,20 m de comprimento e pesar mais de $45 \mathrm{~kg}$ (SILVEIRA, 1969).

O tamanduá-bandeira possui diversas adaptações morfológicas, fisiológicas e comportamentais para seus hábitos alimentares e de defesa, como a presença de garras bem desenvolvidas nas mãos (DRUMOND, 1992). Ele também assume uma posição ereta sustentada pelos membros pélvicos e pela cauda, permitindo uma resposta defensiva contra seus oponentes (DRUMOND, 1992; NOWAK, 1999; DICKMAN, 2001), além disso, realiza atividades de forrageio e possui habilidades para subir em árvores e cupinzeiros altos (YOUNG et al., 2003).

Originalmente o tamanduá-bandeira era encontrado em todos os estados brasileiros, mas atualmente está extinto no Rio de Janeiro, Espírito Santo (MINISTÉRIO DO MEIO AMBIENTE, 2008) e Santa Catarina (CHEREM et al., 2004), e se encontra em declínio populacional nas regiões Sul, Sudeste e Nordeste (FONTANA et al., 2003; MINISTÉRIO DO MEIO AMBIENTE, 2008). Sua distribuição geográfica inicial abrangia desde a América Central até quase toda a extensão da América do Sul (WETZEL, 1985).

De acordo com Miranda e Medri (2010), os estudos populacionais a longo prazo sobre o tamanduábandeira são escassos, não havendo dados sobre sua a longevidade, taxa de sobrevivência ou taxas reprodutivas. Dessa forma estudos envolvendo a anatomia do Myrmecophaga tridactyla tornam-se importantes uma vez que há escassez de informações em todos os níveis sobre a espécie. Assim, objetivou-se com este trabalho descrever a morfologia dos ossos do membro torácico do tamanduá-bandeira, fornecendo dados para estudos sobre esta espécie tão pouco explorada.

\section{Material e Métodos}

O presente trabalho está devidamente registrado no SISBIO (Sistema de Autorização e Informação em Biodiversidade) do ICMBio (Instituto Chico Mendes de Conservação da Biodiversidade) sob o número 31887-1.

Foram utilizados ossos provenientes de dois cadáveres de tamanduá-bandeira (Myrmecophaga tridactyla), coletados em rodovias do estado de Minas Gerais. Os cadáveres foram transportados ao Laboratório de Anatomia Animal da Universidade Federal de Lavras. Para o preparo dos ossos, realizouse inicialmente a retirada dos tecidos moles, para na sequência submetê-los ao processo de maceração 
química de acordo com a técnica preconizada por Rodrigues (2005).

Para a mensuração dos ossos e de seus acidentes foi utilizado paquímetro digital $\left(\right.$ Starret $\left.^{\mathbb{}}\right)$ e para a descrição anatômica dos acidentes ósseos foram empregados termos recomendados pelo International Committee on Veterinary Gross Anatomical Nomenclature (2012) e pela Terminologia Anatômica (SBA, 2001).

\section{Resultados e Discussão}

Verificou-se escassez literária a respeito do tema abordado envolvendo xenarthras, assim será realizada uma comparação dos achados com outros mamíferos.

No presente estudo, a escápula do tamanduábandeira se apresentou como um osso plano, situado lateralmente na porção cranial do tronco, disposto numa inclinação caudodorsal, representando a raiz do membro torácico (DYCE et al., 2010). Encontrou-se isolada do esterno, assim como nos mamíferos domésticos (GETTY, 2008; COLVILLE; BASSERT, 2010; FRANDSON et al., 2010), não havendo nesta região a clavícula como em humanos (VIGUÉ, 2007), gatos (GETTY, 2008), cutias (OLIVEIRA et al., 2009) e pacas (OLIVEIRA et al., 2007). A escápula apresentou uma margem proximal convexa, acentuada mais caudalmente, tornando o ângulo cranial menos evidente do que o ângulo caudal, além de uma margem caudal com aspecto côncavo (Figura 1A), fato que se assemelha ao encontrado na escápula dos humanos, porém com a margem proximal mais plana (VIGUÉ, 2007).

Em sua face lateral, a escápula exibiu uma bem desenvolvida e pronunciada espinha (Figura 1A), medindo cerca de 9,36 cm de comprimento, assim como observado no gato (SOUZA et al., 2009). Esta apresentou em sua extremidade distal o acrômio, similarmente às cutias (OLIVEIRA et al., 2009) e pacas (OLIVEIRA et al., 2007), apresentando comprimento de aproximadamente $5,21 \mathrm{~cm}$, sendo bastante desenvolvido, com contorno semilunar e disposto no sentido craniodistal (Figura 1A) assemelhando-se ao observado no tatu-peba (ALBERTO et al., 2010) e em parte ao do homem (SPALTEHOLZ; SPANNER, 2006). No acrômio notou-se ainda um discreto processo supra-hamato, assim como observado no gato (SOUZA et al., 2009).

A espinha da escápula apresentou ainda em seu terço médio a tuberosidade da espinha da escápula encurvada caudalmente como nos suínos (GETTY, 2008). A espinha da escápula dividiu a face lateral da escápula em duas fossas, a infraespinhal e a supraespinhal

FIGURA 1: Vista das faces lateral (A) e medial (B) e do ângulo distal (C) da escápula do tamanduá-bandeira. Evidencia-se a margem proximal (1), ângulo cranial (2), ângulo caudal (3), margem caudal (4), espinha da escápula (5), acrômio (6), processo suprahamato (7), tuberosidade da espinha da escápula (8), fossa infraespinhal (9), fossa supraespinhal (10), crista longitudinal (11), forame supraespinhal (12), fossa subescapular (13), cavidade glenoide (14), tubérculo supraglenoidal (15), colo da escápula (círculo tracejado) e a incisura da escápula (seta). Escala $1 \mathrm{~cm}$.

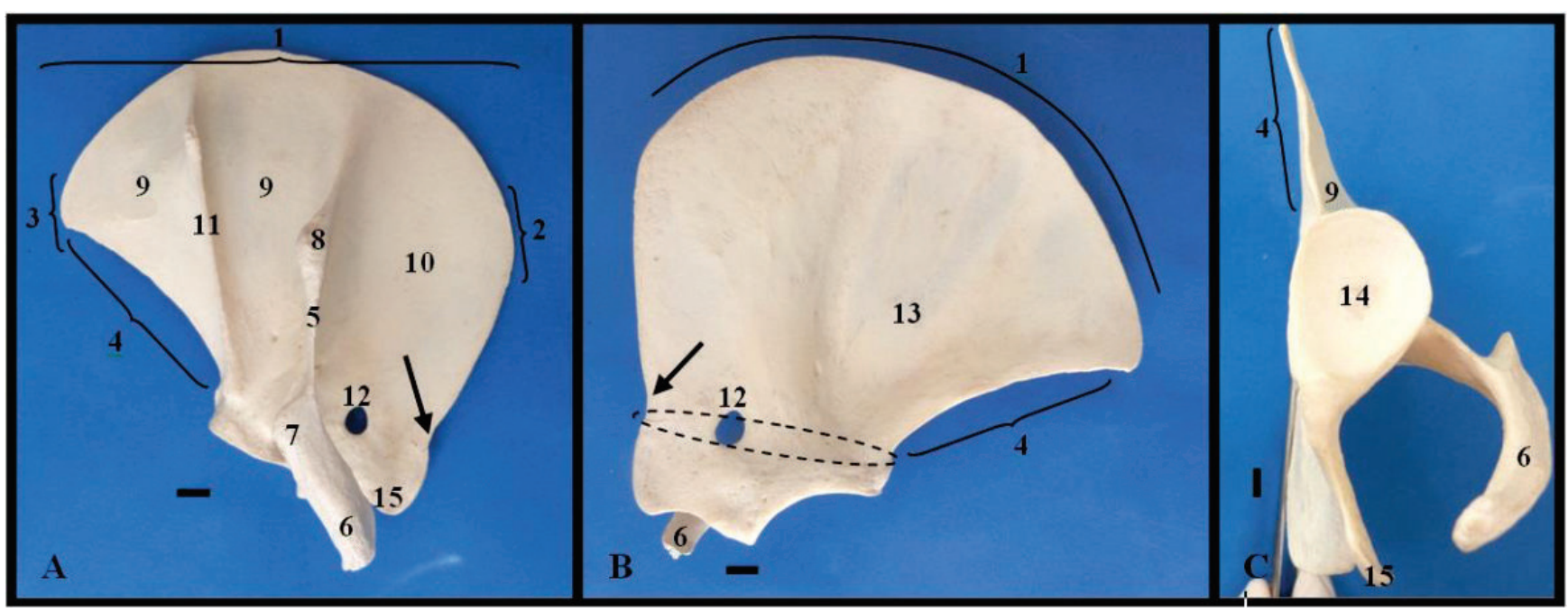


(Figura 1A). A fossa infraespinhal estava dividida por uma bem desenvolvida crista longitudinal (Figura 1A), também observada em humanos (VIGUÉ, 2007), porém, menos acentuada do que a espinha da escápula e com comprimento de $9,39 \mathrm{~cm}$.

No terço distal da fossa supraespinhal, junto ao colo da escápula (Figura 1B), notou-se um forame de formato elipsoide bem evidente, para o qual sugerimos o nome de forame supraespinhal (Figura 1A), com circunferência média de 2,40 cm. Este forame não é observado na escápula de mamíferos domésticos (GODINHO et al., 2001; GETTY, 2008; DYCE et al., 2010), porém, evidenciouse nesta mesma região da escápula humana (GRAAF, 2003) a incisura da escápula que dá passagem ao nervo supraescapular, incisura também observada na escápula do tamanduá-bandeira só que mais discreta (Figura 1A). A fossa supraespinhal da escápula do tamanduá-bandeira apresentou-se mais larga comparativamente à dos mamíferos domésticos (GODINHO et al., 2001; GETTY, 2008; DYCE et al., 2010).
A face medial da escápula apresentou uma superfície côncava, a fossa subescapular (Figura 1B), interrompida por depressões longitudinais correspondentes à espinha da escápula e à crista longitudinal, assim como na escápula humana (DÂNGELO; FATTINI, 2007).

No ângulo distal da escápula do tamanduábandeira evidenciou-se uma cavidade côncava discreta e achatada lateromedialmente, a cavidade glenoide, destinada a se articular com a cabeça do úmero (Figura 1C). Cranioproximalmente a esta cavidade notou-se uma elevação óssea bastante acentuada, o tubérculo supraglenoidal (Figura 1A e 1C). Algumas espécies apresentam junto à face medial do tubérculo supraglenoidal o processo coracoide (DÂNGELO; FATTINI, 2007; GETTY, 2008; DYCE et al., 2010), porém, este não foi observado na escápula do tamanduá-bandeira.

O úmero do tamanduá-bandeira é um osso longo, que se articula proximalmente com a escápula e distalmente com o rádio e a ulna (DYCE et al., 2010). Apresentou-se comprimido craniocaudalmente, exibindo duas faces, cranial e caudal, e duas margens, lateral e medial (Figura 2A), diferentemente do úmero dos

FIGURA 2: Vista das faces caudal (A) e cranial (B) e das margens medial (C) e lateral (D) do úmero do tamanduá-bandeira. Evidenciase a cabeça do úmero (1), tubérculo maior (2), tubérculo menor (3), colo (4), tuberosidade redonda maior (5), crista cranial do tubérculo maior (6), crista do tubérculo menor (7), crista caudal do tubérculo maior (8), tuberosidade deltoide medial (9) e lateral (10), crista do úmero (11), sulco do músculo braquial (12), crista supracondilar medial (seta), crista supracondilar lateral (13), forame supracondilar (14), epicôndilo lateral (15), epicôndilo medial (16), fossa do olécrano ( $\boldsymbol{\nabla})$, tróclea (17), fossa radial (18) e a face do músculo infraespinhal (*). Escala $1 \mathrm{~cm}$.

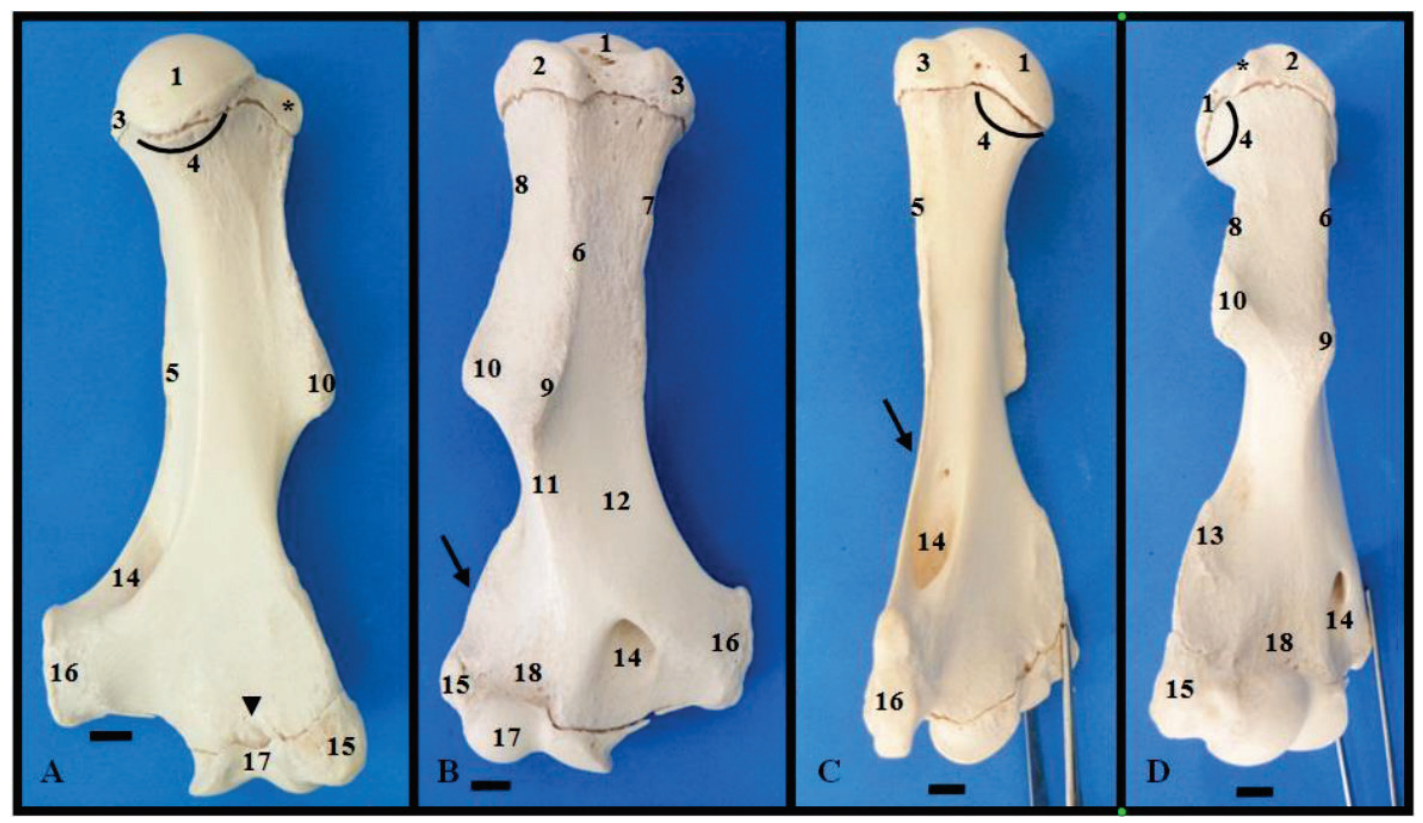


mamíferos domésticos que possui faces cranial, caudal, lateral e medial (GODINHO et al., 2001), apresentando no tamanduá comprimento médio de $17,23 \mathrm{~cm}$.

Em sua extremidade proximal notaram-se dois tubérculos discretos, o menor (medial) e o maior (lateral), que mediram 2,05 e 2,58 cm, respectivamente. O tubérculo menor exibiu a crista do tubérculo menor, pouco evidente, dirigindo-se distalmente até a tuberosidade redonda maior, essa também discreta. $\mathrm{O}$ colo se encontrou na face caudal e distal à cabeça do úmero, diferindo do comumente encontrado em mamíferos domésticos, onde o colo do úmero apresentase bem definido somente na face caudal da extremidade proximal (GODINHO et al., 2001).

Junto à margem medial e aproximadamente no terço médio do úmero do tamanduá-bandeira notouse a discreta tuberosidade do músculo redondo maior. Um pouco distalmente a esta tuberosidade observouse o forame supracondilar, bem desenvolvido e com formato elíptico, apresentando circunferência de 2,57 $\mathrm{cm}$, estando situado entre a tróclea e o epicôndilo medial com abertura proximal na face caudal do úmero e abertura distal em sua face cranial (Figuras 2A, 2B e 2C). O forame supracondilar é característico do úmero de gatos e dá passagem à artéria braquial e ao nervo mediano (GETTY, 2008; DYCE et al., 2010).

Notou-se em sua margem lateral e junto à face caudal do tubérculo maior a face do músculo infraespinhal (Figura 2D). Distalmente a ela observouse a crista caudal do tubérculo maior (Figura 2B e 2D) que se originou neste tubérculo e terminou junto à tuberosidade deltoide lateral (Figura 2A, 2B e 2D). Partindo da face cranial do tubérculo maior, junto à face cranial do úmero do tamanduá-bandeira, notou-se a crista cranial do tubérculo maior (Figura 2B e 2D), bem evidente, e que terminou em outra proeminência bem desenvolvida, a tuberosidade deltoide medial (Figura $2 \mathrm{~B}$ e 2D). Ao se observar distalmente a tuberosidade deltoide medial, percebeu-se uma pouco proeminente e discreta crista do úmero (Figura 2B), que estava associada ao pouco desenvolvido sulco do músculo braquial (Figura 2B), fato não observado em mamíferos domésticos, que possuem a face lateral do úmero lisa e ocupada quase que totalmente pelo sulco do músculo braquial (GODINHO et al., 2001).

A tuberosidade deltoide no tamanduá-bandeira apresentou-se mais desenvolvida do que no tatu-peba (ALBERTO et al., 2010), além de ser par, o que a difere dos relatos em mamíferos domésticos (GODINHO et al., 2001; GETTY, 2008; DYCE et al., 2010). A tuberosidade deltoide se apresentou apenas como uma pequena rugosidade no úmero da paca (OLIVEIRA et al., 2007) e nas cutias (OLIVEIRA et al., 2009), porém, no tamanduá-bandeira e nos mamíferos domésticos (GODINHO et al., 2001; GETTY, 2008; DYCE et al., 2010) é bem proeminente.

$\mathrm{Na}$ extremidade distal do úmero do tamanduábandeira notou-se o côndilo do úmero formado apenas por uma tróclea (Figura 2B), sendo diferente dos mamíferos domésticos que possuem o capítulo e a tróclea (GODINHO et al., 2001; GETTY, 2008; DYCE et al., 2010). Observou-se ainda nesta extremidade o epicôndilo medial (Figura 2A), mais pronunciado e desenvolvido do que o lateral (Figura 2D). Esta característica difere daquelas reportadas para o úmero de mamíferos domésticos (GODINHO et al., 2001; GETTY, 2008; DYCE et al., 2010) e do tatu-peba (ALBERTO et al., 2010) que exibem o epicôndilo lateral mais longo e mais destacado do que o medial.

Notou-se na extremidade distal do úmero duas discretas fossas, a do olécrano e a radial (Figura 2A, 2B e 2D), ao contrário dos relatos em mamíferos domésticos (GODINHO, et al., 2001; GETTY, 2008; DYCE et al., 2010), que possuem a fossa do olécrano bem profunda para receber o processo ancôneo da ulna (GODINHO et al., 2001; GETTY, 2008; DYCE et al., 2010). Constatou-se ainda nesta região a presença de duas cristas supracondilares, uma medial (Figura 2B e 2C) e outra lateral (Figura 2D), ambas proeminentes e bem evidentes. A primeira surgiu da extremidade proximal do epicôndilo medial para terminar junto à tuberosidade redonda maior e a segunda da extremidade proximal ao epicôndilo lateral. Cabe ressaltar que a crista medial não é relatada no úmero dos mamíferos domésticos (GODINHO et al., 2001; GETTY, 2008; DYCE et al., 2010). 
O osso rádio do tamanduá-bandeira é um osso longo, com cerca de $18,8 \mathrm{~cm}$ de comprimento, que apresenta duas margens, lateral e medial, e duas faces, cranial e caudal (Figuras 3A e 3B). Na face cranial do rádio notou-se uma crista proeminente que se estendeu do terço proximal do corpo à sua tróclea, medindo aproximadamente 12,8 cm de comprimento (Figura 3A). Ela delimitou dois amplos sulcos extensores, um no seu aspecto medial e outro no seu aspecto lateral, cada um medindo 2,04 cm e 1,21 cm de largura, respectivamente (Figura 3A). Exibiu ainda uma ampla superfície flexora na face caudal dessa mesma extremidade (Figura 3B).

O rádio apresentou na extremidade proximal de sua cabeça uma superfície articular, levemente côncava para articulação com o côndilo do úmero, a fóvea da cabeça do rádio (Figura $3 \mathrm{C}$ ) e junto à margem caudal da cabeça do rádio notou-se uma superfície articular convexa, a circunferência articular (Figuras 3A e 3C), ambos da mesma forma que nos carnívoros domésticos (GETTY, 2008; DYCE et al., 2010) e no homem (DÂNGELO; FATTINI, 2007). A tuberosidade radial se apresentou de forma bem proeminente no rádio do tamanduá-bandeira (Figuras 3A, 3B e 3C).

O rádio e a ulna do tamanduá-bandeira não apresentaram nenhum grau de fusão assim como no homem (DÂNGELO; FATTINI, 2007), nos carnívoros domésticos (GETTY, 2008; DYCE et al., 2010) e na cutia (OLIVEIRA et al., 2009). Eles se articularam proximalmente por meio da incisura radial da ulna e da circunferência articular do rádio (Figuras 3A e 3C)

FIGURA 3: Vista das faces cranial (A), caudal (B) e da epífise proximal (C) do rádio do tamanduá-bandeira. Evidencia-se a margem lateral (1) e medial (2), colo do rádio (3), tróclea (4), crista da face cranial (5), sulco extensor lateral (6), sulco extensor medial (7), superfície extensora (8), processo estiloide do rádio (9), fóvea da cabeça do rádio (10), circunferência articular (11), tuberosidade radial (12) e incisura ulnar (13). Escala $1 \mathrm{~cm}$.

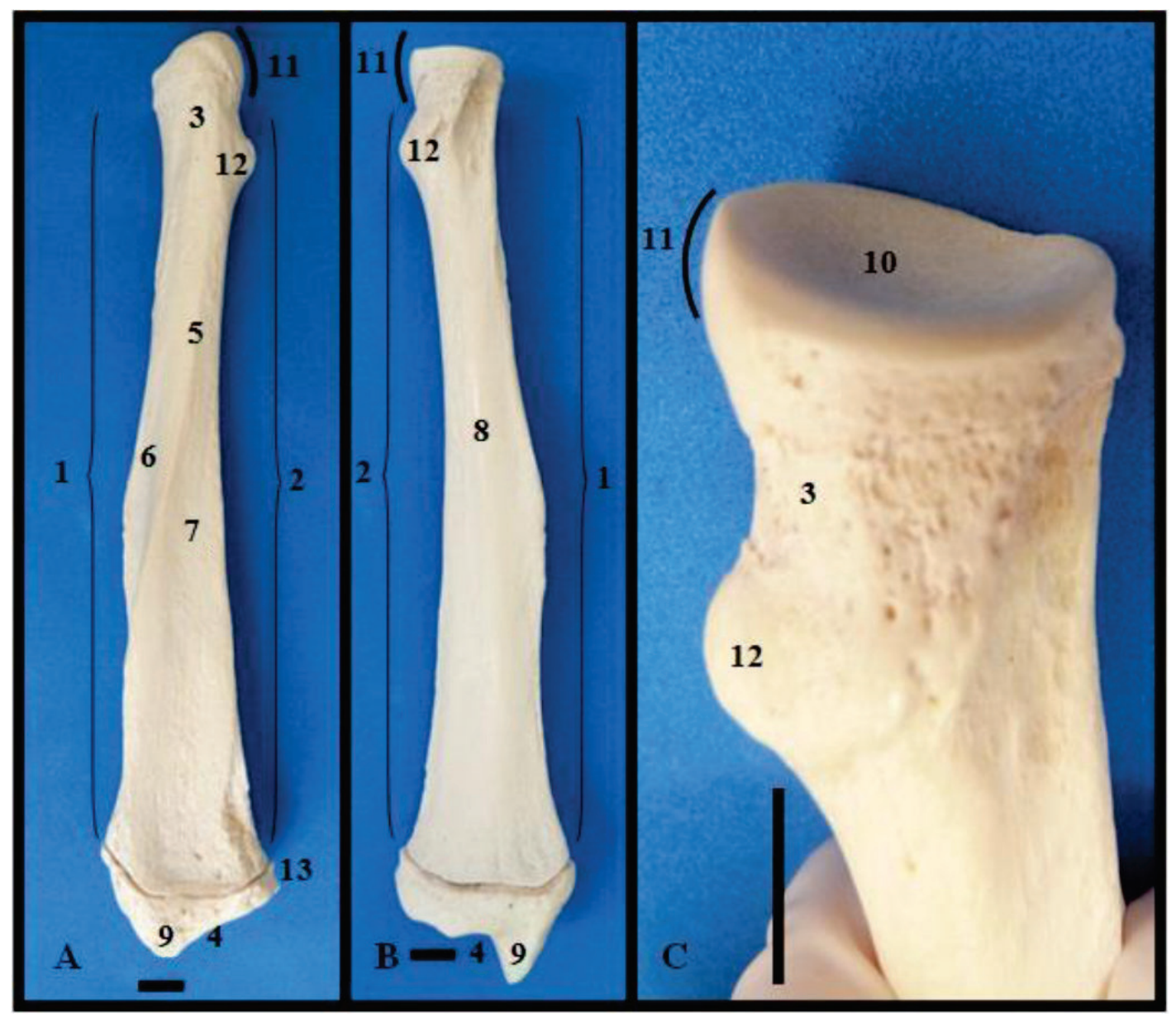


e distalmente pela incisura ulnar do rádio (Figura 3A) e circunferência articular da ulna, da mesma forma que nos carnívoros domésticos (GETTY, 2008; DYCE et al., 2010) e no homem (DÂNGELO; FATTINI, 2007).

As amplas superfícies apresentadas tanto na face cranial quanto na face caudal do rádio do tamanduábandeira, demonstraram que seus músculos extensores e flexores do carpo e dos dedos são bem desenvolvidos. Tal alusão também pode ser feita pelo fato de exercerem muita força com seus membros torácicos em suas atividades alimentares (DRUMOND, 1992; NOWAK, 1999; DICKMAN, 2001).

A ulna do tamanduá-bandeira se apresentou bem desenvolvida, sendo classificada como osso longo e medindo aproximadamente $23,38 \mathrm{~cm}$. Exibiu duas faces, lateral e medial, e duas margens, cranial e caudal (Figura 4A, 4B e 4C). Na margem cranial, destacou-se uma crista

FIGURA 4: Vista da margem cranial (A) e das faces medial (B) e lateral (C) da ulna do tamanduá-bandeira. Evidencia-se o olécrano (1), crista da margem cranial (2), processo ancôneo (3), incisura troclear (4), incisura radial (5), processos coronoides medial (6) e lateral (7), tuberosidade do olécrano (8), processo estiloide da ulna (9) e faceta articular para o osso ulnar do carpo (10). Escala $1 \mathrm{~cm}$.

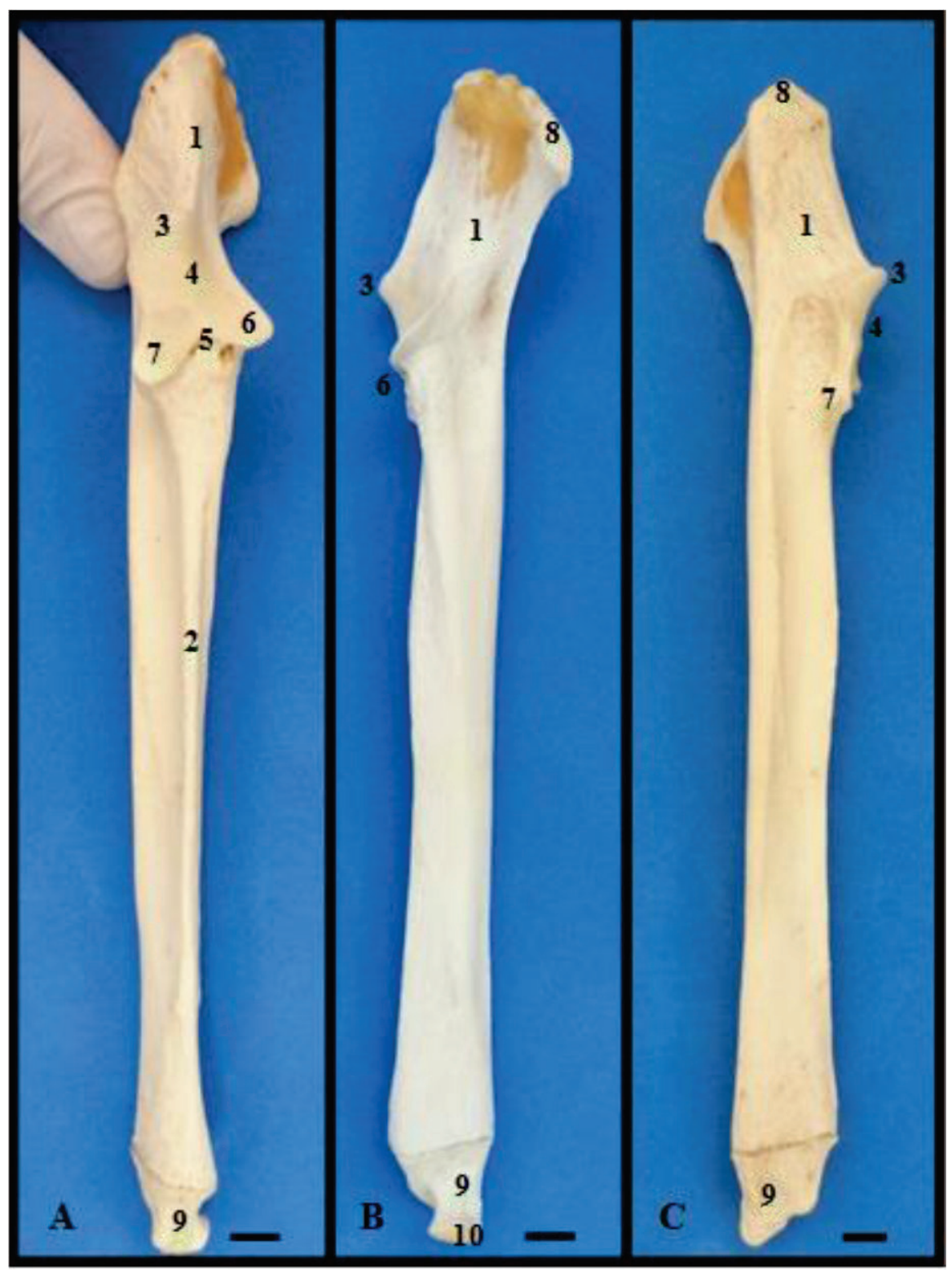


proeminente que se estendeu do terço proximal do corpo ao processo estiloide (Figura 4A).

O processo ancôneo da ulna do tamanduá-bandeira se apresentou como uma pequena proeminência (Figura 4A, 4B e 4C), as incisuras troclear e radial são levemente côncavas (Figura 4A e 4C) e ambas são pouco desenvolvidas. $\mathrm{O}$ processo coronoide medial se mostrou mais desenvolvido e proeminente que o lateral (Figura 4A) da mesma forma que nos carnívoros domésticos (GETTY, 2008; DYCE et al., 2010).

A tuberosidade do olécrano do tamanduá-bandeira se apresentou trifacetada e o processo estiloide bem desenvolvido, sendo pronunciado e afilado (Figura 4A, 4B e 4C), apresentando apenas uma faceta articular, para articulação com o osso ulnar do carpo (Figura 4B), assim como nos bovinos (GODINHO et al., 2001), porém, distinto dos carnívoros (GETTY, 2008; DYCE et al., 2010) e dos pequenos ruminantes (GODINHO et al., 2001), nos quais a ulna articula-se com os ossos ulnar e acessório do carpo.

A ulna do tamanduá-bandeira cruzou obliquamente a face caudal do rádio no sentido mediolateral, disposição também exibida pela ulna dos carnívoros domésticos (GETTY, 2008; DYCE et al., 2010), do homem (DÂNGELO; FATTINI, 2007) e da paca (OLIVEIRA, 2007), formando um espaço interósseo amplo e único, o que lhes permite executar movimentos de rotação de grande amplitude, fato descrito nos carnívoros (GETTY, 2008; DYCE et al., 2010) e no homem (DÂNGELO; FATTINI, 2007). Esses movimentos são realizados pelos tamanduás-bandeira tanto para destruir formigueiros e cupinzeiros quanto para se defender de qualquer ameaça a que estejam sujeitos (DRUMOND, 1992; NOWAK, 1999; DICKMAN, 2001).

No tamanduá-bandeira o carpo mostrou-se formado por oito ossos dispostos em duas fileiras, uma proximal e outra distal, assemelhando-se ao do homem (VIGUÉ, 2007). A fileira proximal compôs-se no sentido mediolateral pelos ossos radial, intermédio, ulnar e acessório do carpo (Figura 5A e 5B), que em humanos são denominados, respectivamente, escafoide, semilunar, piramidal e pisiforme (DÂNGELO; FATTINI, 2007; VIGUÉ, 2007). Em cães, os ossos intermédio e radial do carpo estão fusionados, ocorrendo por este motivo sete ossos no carpo (EVANS, 2001; GETTY, 2008; DYCE et al., 2010). A fileira distal, por sua vez, mostrou-se composta no mesmo sentido pelos ossos cárpicos I, II, III e IV (Figura 5A e 5B), da mesma forma que nos cães (EVANS, 2001; GETTY, 2008; DYCE et al., 2010) e no o homem (DÂNGELO; FATTINI, 2007; VIGUÉ, 2007), denominados, respectivamente, trapézio, trapezoide, capitato e hamato. Entre as duas fileiras do carpo, junto à face medial, encontrou-se um osso sesamoide do músculo abdutor longo do primeiro dedo, este, presente no carpo dos carnívoros domésticos (GETTY, 2008; DYCE et al., 2010) e ausente no homem (DÂNGELO; FATTINI, 2007; VIGUÉ, 2007). A morfologia dos ossos do carpo se assemelhou mais àquela observada em humanos (DÂNGELO; FATTINI, 2007; VIGUÉ, 2007).

No tamanduá-bandeira foram observados cinco ossos metacárpicos denominados da face medial para lateral como I, II, III, IV e V. São ossos longos que se dividiram proximodistalmente em base, corpo e cabeça. Todos apresentaram em sua base proeminências para fixação de músculos e ligamentos (Figuras 5A e 5B). Todas essas características se assemelham aos metacárpicos de humanos (DÂNGELO; FATTINI, 2007; VIGUÉ, 2007) e de cães (EVANS, 2001; GETTY, 2008; DYCE et al., 2010).

O metacárpico I mostrou-se como um osso de tamanho bastante reduzido (Figuras 5A e 5B), se apresentando no homem dessa mesma forma, porém, mais espesso (DÂNGELO; FATTINI, 2007; VIGUÉ, 2007). A face palmar do metacárpico I mostrou-se ligeiramente côncava e nela se observaram dois ossos sesamoides assemelhando-se ao homem (DÂNGELO; FATTINI, 2007; VIGUÉ, 2007), e diferindo dos cães, por estes apresentarem apenas um sesamoide nesta região (EVANS, 2001; GETTY, 2008; DYCE et al., 2010).

O metacárpico II exibiu no dorso de seu corpo uma crista evidente (Figura 5A). Junto à face palmar de sua cabeça encontraram-se dois ossos sesamoides assim como observado em cães (EVANS, 2001; GETTY, 2008; DYCE et al., 2010). 
FIGURA 5: Vista da face dorsal (A) e palmar (B) da mão direita do tamanduá-bandeira. Evidenciam-se os ossos radial (1), intermédio (2), ulnar (3) e acessório do carpo (4), cárpico I (5), cárpico II (6), cárpico III (7), cárpico IV (8), metacárpico I (9), metacárpico II (10), metacárpico III (11), metacárpico IV (12), metacárpico V (13). No dedo I observam-se as falanges proximal (14) e distal (15). No dedo II observam-se as falanges proximal (16), média (17) e distal (18). No dedo III observam-se as falanges proximal (19), média (20) e distal (21). No dedo IV observam-se as falanges proximal (22), média (23) e distal (24). No dedo V observam-se as falanges proximal (25) e distal (26). Escala $1 \mathrm{~cm}$.

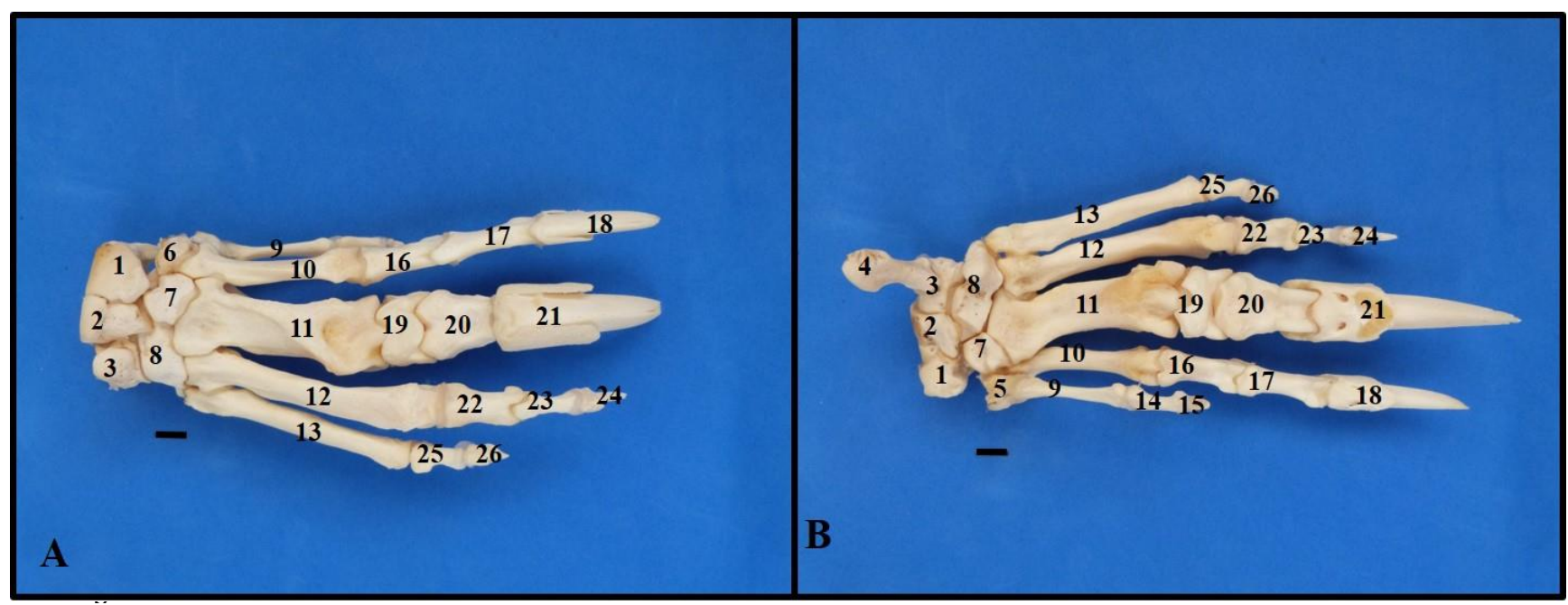

O metacárpico III foi o osso mais desenvolvido dos metacárpicos do tamanduá-bandeira (Figuras 5A e 5B). Seu corpo exibiu quatro faces: dorsal, palmar, lateral e medial. Em sua face dorsal evidenciou-se uma crista bem proeminente que se dividiu em duas a partir do terço médio no sentido proximodistal para delimitar uma depressão de formato triangular. Sua cabeça apresentou uma tróclea com uma proeminente crista sagital para articulação com a falange proximal do dedo III. Sua face palmar articulou-se com dois ossos sesamoides, da mesma forma que em cães (EVANS, 2001; GETTY, 2008; DYCE et al., 2010).

O osso metacárpico IV foi o mais longo dos ossos metacárpicos do tamanduá-bandeira (Figura 5A e 5B). A face palmar do seu corpo apresentou uma crista no terço distal pouco pronunciada e junto à face palmar da cabeça notou-se apenas um osso sesamoide bem desenvolvido, diferentemente dos relatos em humanos (DÂNGELO; FATTINI, 2007; VIGUÉ, 2007) e cães (EVANS, 2001; GETTY, 2008; DYCE et al., 2010).

$\mathrm{O}$ osso metacárpico $\mathrm{V}$ exibiu uma cabeça com formato arredondado diferindo dos ossos metacárpicos II, III e IV. Notaram-se dois ossos sesamoides junto à face palmar da cabeça do metacárpico $\mathrm{V}$, igualmente ao relatado em cães (EVANS, 2001; GETTY, 2008; DYCE et al., 2010).

O dedo I do tamanduá-bandeira apresentou duas falanges, proximal e distal (Figura 5B), igualmente aos cães (EVANS, 2001; GETTY, 2008; DYCE et al., 2010) e ao homem (DÂNGELO; FATTINI, 2007; VIGUÉ, 2007). Sua falange distal, assim como as demais da mão do tamanduá-bandeira, exibiu um tubérculo flexor, uma crista e um processo ungueal, (Figuras 5A e 5B), da mesma forma que nos cães (EVANS, 2001; GETTY, 2008; DYCE et al., 2010).

O dedo II apresentou três falanges: proximal, média e distal (Figura 5A e 5B). A base da falange proximal mostrou-se mais larga que a sua cabeça. A face palmar apresentou-se côncava e sua cabeça exibiu um côndilo para articulação com a falange média. A falange média apresentou base, corpo e cabeça, existindo um osso sesamoide entre esta e a falange distal. A falange distal exibiu dois forames soleares, um medial e outro lateral, presentes também nas falanges distais dos dedos III, IV e V do tamanduá-bandeira.

O dedo III foi o mais desenvolvido dos cinco dedos do tamanduá-bandeira. Apresentou três falanges: proximal, média e distal (Figura 5A e 5B). A falange 
proximal se apresentou como um osso curto, não sendo observadas descrições morfológicas semelhantes nos mamíferos domésticos (GETTY, 2008; DYCE et al., 2010). A falange média se mostrou como um osso longo e seu corpo exibiu uma depressão bem pronunciada em sua face palmar. Entre as falanges média e distal observou-se um osso sesamoide.

$\mathrm{O}$ dedo IV apresentou três falanges: proximal, média e distal (Figura 5A e 5B), com um osso sesamoide entre as falanges proximal e média. Além disso, suas falanges média e distal apresentaram tamanho reduzido.

$\mathrm{O}$ dedo $\mathrm{V}$ apresentou duas falanges, proximal e distal (Figura 5A e 5B), diferentemente do homem (DÂNGELO; FATTINI, 2007; VIGUÉ, 2007) e dos cães (EVANS, 2001; GETTY, 2008; DYCE et al., 2010) que apresentam três falanges. Entre as falanges proximal e distal observou-se um osso sesamoide. A falange distal apresentou tamanho bastante reduzido, além da crista e do processo ungueais rudimentares.

No estudo descritivo dos ossos do membro torácico do tamanduá-bandeira (Myrmecophaga tridactyla) pode-se notar que alguns acidentes ósseos se destacaram dos demais, conferindo-lhes características próprias e distintas dos mamíferos domésticos e de alguns silvestres como cutias, pacas e tatus-peba, porém, percebeu-se que a escápula se assemelhou à do homem. $\mathrm{O}$ úmero apresentou morfologia totalmente distinta das descrições já feitas para o homem, mamíferos domésticos e alguns silvestres como cutias e pacas, porém, guardou semelhanças estreitas com a do tatu-peba. $\mathrm{O}$ rádio e a ulna apresentaram-se morfologicamente semelhantes aos de carnívoros domésticos e do homem, fato atribuído ao tipo de atividades que os membros torácicos realizam, relacionadas principalmente aos seus hábitos alimentares e defesa. Quanto à mão, notou-se variação no número de ossos do carpo, falanges e sesamoides em comparação com humanos e carnívoros domésticos, mas com relação à morfologia, foram encontradas semelhanças entre as espécies citadas.

\section{Agradecimentos}

Este trabalho foi realizado com apoio financeiro do Conselho Nacional de Desenvolvimento Científico e Tecnológico (CNPq), da Fundação de Amparo à Pesquisa do Estado de Minas Gerais (FAPEMIG) e da Universidade Federal de Lavras (UFLA).

\section{Referências}

ALBERTO, M. L. V.; OLIVEIRA, C. M.; RODRIGUES, M. N.; OLIVEIRA, A. B.; MIGLINO, M. A.; AMBRÓSIO, C. E. Funções ósseas do esqueleto de tatu (Euphractus sexcinctus). Acta Veterinaria Brasilica, São Paulo, v. 4, n. 2, p. 86-91, 2010.

CHEBEZ, J. C. Los que se Van. Buenos Aires: Albatros, 1994. $604 \mathrm{p}$.

CHEREM, J. J.; SIMÕES-LOPES, P. C.; ALTHOFF, S.; GRAIPEL, M. E. Lista dos mamíferos do estado de Santa Catarina, sul do Brasil. Mastozoología Neotropical, Mendoza, v. 11, n. 2, p. 151184, 2004

COLVILLE, T.; BASSERT, J. M. Anatomia e fisiologia clínica para medicina veterinária. 2. ed. Rio de Janeiro: Elsevier, 2010. $543 \mathrm{p}$.

DÂNGELO, J. G.; FATTINI, C. A. Anatomia humana sistêmica e segmentar. São Paulo: Atheneu, 2007. 763 p.

DICKMAN, C. R. Anteaters. In: MACDONALD, D. (Ed.). The new encyclopedia of mammals. Oxford: Oxford University Press, 2001, p. 786-787.

DRUMOND, M. A. Padrões de forrageamento do tamanduábandeira (Myrmecophaga tridactyla) no Parque Nacional da Serra da Canastra: dieta, comportamento alimentar e efeito de queimadas. 1992. 95 f. Dissertação (Mestrado em Ecologia) Universidade Federal de Minas Gerais, Belo Horizonte. 1992.

DYCE, K. M.; SACK, W. O.; WENSING, C. J. G. Tratado de anatomia veterinária. 4 ed. Rio de Janeiro: Guanabara Koogan, 2010.834 p.

EMMONS, L. H.; FEER, F. Neotropical rainforest mammals: a field guide. 2. ed. Chicago: The University of Chicago Press, 1997. $307 \mathrm{p}$.

EVANS, H. E. Guia para dissecação do cão. 5. ed. Rio de Janeiro: Guanabara Koogan, 2001. 250p.

FONTANA, C. S.; BENKE, G. A.; REIS, R. E. Livro vermelho da fauna ameaçada de extinção no Rio Grande do Sul. Porto Alegre: EDIPUCRS, 2003. 632 p.

FRANDSON, R. D.; WILKE, W. L.; FAILS, A. D. Anatomia e fisiologia dos animais de fazenda. 6 ed. Rio de Janeiro: Guanabara Koogan, 2010. 454 p.

GETTY, R. Osteologia do carnívoro. In: GETTY, R. (Ed.). Sisson/ Grossman Anatomia dos animais domésticos. Vol. 2. 5 ed. Rio de Janeiro: Guanabara Koogan, 2008. p. 1337-1412.

GODINHO, H. P.; CARDOSO, F. M.; CASTRO, A. C. S. Esqueleto. In: GODINHO, H. P.; CARDOSO, F. M.; CASTRO, A. C. S. (Ed.). Anatomia dos ruminantes domésticos. Belo Horizonte, 2001. p. 8-34. 
GRAAF, K. M. V. Anatomia humana. 6 ed. Barueri: Manole, 2003. $840 \mathrm{p}$

INTERNATIONAL COMMITTEE ON VETERINARY GROSS ANATOMICAL NOMENCLATURE. Nomina anatomica veterinaria. 5 ed. Knoxville: Editorial Committee, 2012. 177 p.

MINISTÉRIO DO MEIO AMBIENTE. Livro vermelho da fauna brasileira ameaçada de extinção. 1 ed. Brasília: MMA, 2008. $1420 \mathrm{p}$.

MIRANDA, F.; MEDRI, I. 2010. Myrmecophaga tridactyla IUCN Red list of threatened species. 2012. Disponível em: $<\mathrm{http}: / /$ www.iucnredlist.org/details/14224/0>. Acesso em: 5 maio 2013.

NOWAK, R. M. Walker's mammals of the world. Vol. 1. 6 ed. Baltimore and London: The Johns Hopkins University Press, 1999. $836 \mathrm{p}$.

OLIVEIRA, F. S.; CANOLA, J. C.; MACHADO, M. R. F.; CAMARGO, M. H. B. Descrição anátomo-radiográfica do esqueleto apendicular da paca (Agouti paca). Acta Scientiae Veterinariae, Porto Alegre, v. 35, n. 1, p. 83-87, 2007.

OLIVEIRA, F. S.; MARTINS, L. L.; PAULONI, A. P.; TONIOLLO, G. H.; CANOLA, J. C.; MACHADO, M. R. F. Descrição anátomoradiográfica do esqueleto apendicular da cutia (Dasyprocta azarae, Lichtenstein, 1823). Ars Veterinaria, Jaboticabal, v. 25, n. 1, p. 28-31, 2009.

RODRIGUES, H. Técnicas anatômicas. 3. ed. Vitória: Arte Visual, 2005. 229 p.
SBA - SOCIEDADE BRASILEIRA DE ANATOMIA. Terminologia anatômica: comissão federativa da terminologia anatômica, terminologia anatômica internacional. 1. ed. São Paulo: Manole, 2001. 248 p.

SILVEIRA, E. K. P. História natural do tamanduá-bandeira, Myrmecophaga tridactyla Linnaeus 1758, Myrmecophagidae. Vellozia, Rio de Janeiro, v. 7, p. 34-43, 1969.

SOUZA, J. B. S.; FILHO, J. A. C. L.; CRUZ, J. A. L. O.; SANTOS, R. M. B. Estudo da anatomia comparada entre as escápulas dos esqueletos do museu de anatomia da UFRPE como complemento de aulas de osteologia. In: JEPEX, 9, 2009, Recife. Anais... Recife: UFRPE, 2009. Versão eletrônica.

SPALTEHOLZ, W.; SPANNER, R. Anatomia humana: atlas e texto. São Paulo: Roca, 2006. 902 p.

VIGUÉ, J. Grande atlas do corpo humano: anatomia, histologia, patologias. Barueri: Manole, 2007. 560 p.

WETZEL, R. M. The identification and distribution of recent Xenarthra (= Edentata). In: MONTGOMERY, G. G. (Ed.). The evolution and ecology of armadillos, sloths and vermilinguas. Washington and London: Smithsonian Institution Press, 1985. p. 5-21.

YOUNG, R. J.; COELHO, C. M.; WIELOCH, D. R. A note on the climbing abilities of giant anteaters, Myrmecophaga tridactyla (Xenarthra, Myrmecophagidae). Boletim do Museu de Biologia Mello Leitão, Santa Teresa, v. 15, p. 41-46, 2003. 